\title{
The Influence of Regional
} Distribution and Pharmacologic Specificity of $\mathrm{GABA}_{A} R$ Subtype Expression on Anesthesia and Emergence

\author{
Iris Speigel ${ }^{1,2}$, Edyta K. Bichler ${ }^{1,2}$ and Paul S. García ${ }^{1,2 *}$ \\ ${ }^{1}$ Department of Anesthesiology, Emory University School of Medicine, Atlanta, GA, United States, ${ }^{2}$ Research Division, \\ Atlanta Veteran's Affairs Medical Center, Atlanta, GA, United States
}

Anesthetics produce unconsciousness by modulating ion channels that control neuronal excitability. Research has shown that specific $G A B A_{A}$ receptor $\left(G A B A_{A} R\right)$ subtypes in particular regions of the central nervous system contribute to different hyperpolarizing conductances, and behaviorally to distinct components of the anesthetized state. The expression of these receptors on the neuron cell surface, and thus the strength of inhibitory neurotransmission, is dynamically regulated by intracellular trafficking mechanisms. Pharmacologic or activity-based perturbations to these regulatory systems have been implicated in pathology of several neurological conditions, and can alter the individual response to anesthesia. Furthermore, studies are beginning

OPEN ACCESS

Edited by:

Richard Bernard Mailman, Penn State College of Medicine,

United States

Reviewed by:

Li Zhang,

National Institutes of Health,

United States

Elif Engin,

McLean Hospital, United States

*Correspondence:

Paul S. García pgarcia@emory.edu

Received: 11 April 2017 Accepted: 19 July 2017 Published: 22 August 2017

Citation:

Speigel I, Bichler EK and García PS (2017) The Influence of Regional Distribution and Pharmacologic Specificity of $G A B A_{A} R$ Subtype

Expression on Anesthesia and Emergence.

Front. Syst. Neurosci. 11:58. doi: 10.3389/fnsys.2017.00058 to uncover how anesthetic exposure itself elicits enduring changes in subcellular physiology, including the processes that regulate ion channel trafficking. Here, we review the mechanisms that determine $\mathrm{GABA}_{A} \mathrm{R}$ surface expression, and elaborate on influences germane to anesthesia and emergence. We address known trafficking differences between the intrasynaptic receptors that mediate phasic current and the extra-synaptic receptors mediating tonic current. We also describe neurophysiologic consequences and network-level abnormalities in brain function that result from receptor trafficking aberrations. We hypothesize that the relationship between commonly used anesthetic agents and $\mathrm{GABA}_{A} \mathrm{R}$ surface expression has direct consequences on mature functioning neural networks and by extension ultimately influence the outcome of patients that undergo general anesthesia. Rational design of new anesthetics, anesthetic techniques, EEG-based monitoring strategies, or emergence treatments will need to take these effects into consideration.

Keywords: GABA, receptor trafficking, surface expression, extra-synaptic receptors, tonic inhibition, anesthesia, POCD

\section{INTRODUCTION}

Anesthetics generate the most recognizable feature of general anesthesia, unconsciousness, by modulating ion channels in the central nervous system, especially the $G_{A B A}$ receptor $\left(G A B A_{A} R\right)$ (Garcia et al., 2010). The exposure of $\mathrm{GABA}_{\mathrm{A}} \mathrm{Rs}$ to neurotransmitters and modulators (e.g., benzodiazepines and anesthetics) depends on the number and distribution of receptors existing 
on the cell surface in a particular brain region. In addition to abundance, variation is also an important determinant of GABAergic signaling. The most prominent classifying features are receptor proximity to the synapse and the type of current it mediates, with subtypes broadly characterized as "intra-synaptic" receptors mediating phasic currents or "extra-synaptic" receptors mediating tonic currents. Mutagenic and recombinant studies have demonstrated that these subtypes have profound intrinsic differences in sensitivity to GABA, pharmacologic modulation, and anesthetic agents. These subtype-specific interactions are critical to understanding how modulation of inhibitory neurotransmission is achieved under clinical or diseased conditions, and to interpreting the basis for neuron ensemble activity patterns that manifest during anesthesia, e.g., those reflected by electroencephalograph (EEG) recordings. The clinical implication is that subtle differences in the CNS distribution or expression levels of certain $\mathrm{GABA}_{\mathrm{A}} \mathrm{R}$ subtypes could underlie phenotypic differences in sensitivity to anesthesia. These differences might manifest as problems related to appropriate dosing of anesthetic drugs (i.e., as an increased risk of awareness with recall) during surgery or as an enhanced sensitivity to the hypoactivity commonly encountered in the immediate post-anesthesia period, emergence. Moreover, increased functional knowledge of region-specific as well as subcellular localization of $\mathrm{GABA}_{\mathrm{A}} \mathrm{R}$ subtypes may hold the key to understanding the neurological consequences of anesthesia, e.g., emergence complications, delirium, or long-term cognitive dysfunction.

Many drugs which modulate $\mathrm{GABA}_{\mathrm{A}} \mathrm{R}$ channel function also change surface expression of $\mathrm{GABA}_{\mathrm{A}} \mathrm{Rs}$, e.g., flumazenil (Kuver and Smith, 2016), alcohol (Gonzalez et al., 2012), and neurosteroids (Abramian et al., 2014). Interestingly, recent studies demonstrate that anesthetic agents may as well (Zurek et al., 2014; Li et al., 2015). This review will describe pharmacologic and activity based influences on $\mathrm{GABA}_{\mathrm{A}} \mathrm{R}$ surface expression and its relationship to anesthesia and emergence. We will review what is known (and what is unknown) regarding brain region specificity of $G_{A B A} R$ subtypes and how the $\mathrm{GABA}_{\mathrm{A}} \mathrm{R}$ landscape might change during surgical anesthesia. Then, we will outline how $\mathrm{GABA}_{A} \mathrm{R}$ surface expression is dynamically maintained by trafficking between subcellular compartments, and specify where subtype variability imparts important functional and trafficking properties. We will also illustrate how subtype-specific surface expression underlies inhibitory signaling and how subtype heterogeneity underlies the behavioral endpoints of anesthesia. Finally, we discuss how trafficking changes can alter clinical sensitivity to anesthesia, and how trafficking phenotypes may contribute to complications in the recovery of cognitive functions from anesthesia.

\section{MODULATION OF GABA $A_{A}$ Rs IN THE CNS BY ANESTHETICS}

Physiologically, drugs that produce general anesthesia for use in surgery cause a progressive depression of electrochemical communication among cells in the central nervous system. The cardinal target of anesthesia, consciousness, is supported by a network of arousal centers residing in subcortical nuclei. These excitatory projections connect to each other and to the rest of the brain. In turn, these nuclei receive inhibitory projection from the hypothalamus (preoptic area), the thalamus, and the cortex (Silber and Rye, 2001). The predominate explanation for the process of initiating unconsciousness is that when anesthetic agents infuse the brain during induction, this network of interdependent excitatory/inhibitory connections is disturbed, and the arousal nuclei decrease neurotransmitter output (Brown et al., 2011). Ultimately, the diminished excitatory drive onto pyramidal neurons of the cortex and thalamus causes network activity to collapse, leading to a decrease in cortical activity, energy, and integration of information - ultimately a state of quiescence (Mashour et al., 2005; Alkire et al., 2008; Brown et al., 2011).

While they primarily generate unconsciousness (and other endpoints of anesthesia) by actions on ion channels in the central nervous system, an important caveat to this paradigm is that anesthetics have molecular targets on many other proteins in the body (Pan et al., 2008). In neurons, affected processes include cellular housekeeping systems such as mitochondrial transition, calcium homeostasis, and actin polymerization (Platholi et al., 2014; Vutskits and Xie, 2016). "Off-target" effects can underlie catastrophic patient reactions, such as the hypersensitivity of skeletal muscle ryanodine receptor channel function to volatile agents in malignant hyperthermia (Correia et al., 2012). Subtler effects with latent complications are suspected in the development of several neurodegenerative diseases, namely Alzheimers' via $\beta$-Amyloid (Xie and $\mathrm{Xu}$, 2013). Later, we review anesthetic-protein interactions in the second messenger signaling protein pathways known to control $\mathrm{GABA}_{\mathrm{A}} \mathrm{R}$ trafficking. Of non-ion channel proteins, there are no obvious structural motifs of the intracellular protein targets of anesthetics.

\section{GABA $_{A} R$ DIVERSITY AND DISTRIBUTION}

The crystallized $\mathrm{GABA}_{\mathrm{A}} \mathrm{R}$ structure was reported in 2014 (Miller and Aricescu, 2014). GABA $\mathrm{A}$ s are related by protein homology to of the Cys-loop superfamily of ligand-gated ion channels, which share similarities with the prokaryotic gleobacter ligand gated ion channel (Nury et al., 2011). $\mathrm{GABA}_{\mathrm{A}} \mathrm{Rs}$ assemble into heteropentamers from 19 different possible subunits that are classified by protein sequence homology as $\alpha 1-6, \beta 1-3, \gamma 1-3, \delta, \varepsilon, \theta$, or $\rho 1-2$. Most naturally occurring receptors contain two $\alpha$, two $\beta$, and either a $\gamma$ or $\delta$ subunit, with $\alpha 1 \beta 2 \gamma 2$ being the most abundant subtype in the mammalian CNS (McKernan and Whiting, 1996). Only nine different configurations are unequivocally expressed in abundance in the mammalian brain (Olsen and Sieghart, 2008). Table 1 describes some of the known research of these configurations. Individual subunit combinations are unique with respect to their pharmacology (Olsen and Sieghart, 2008), distribution among different brain regions (Wisden and Seeburg, 1992), cell-type specific expression (Lee and 
TABLE 1 | GABA $A_{A} R$ subtype diversity and anatomical distribution.

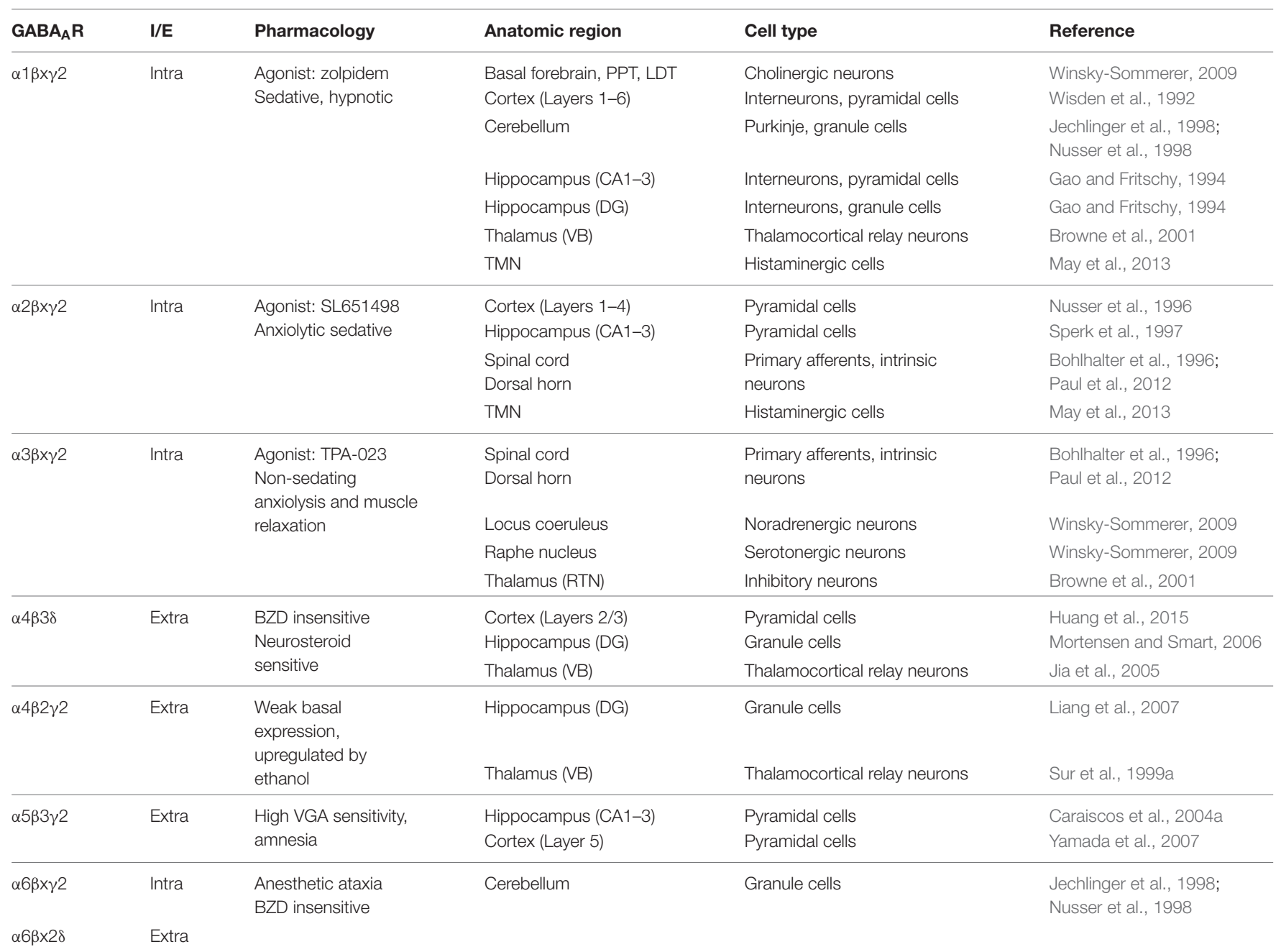

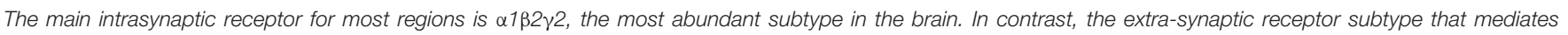

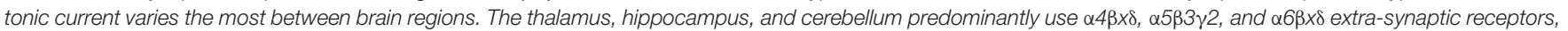

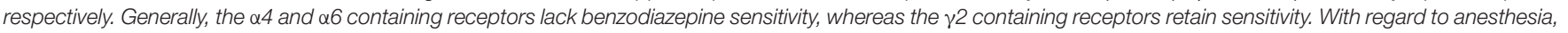

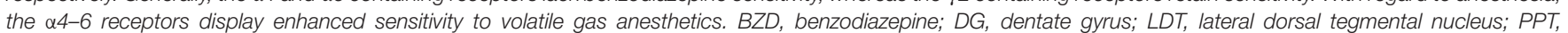

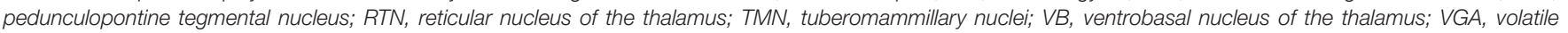
gas anesthetic.

Maguire, 2014), and subcellular localization (Mody and Pearce, 2004).

For all these receptors, the primary endogenous ligand is GABA, which gates the chloride-permeable ion channel pore. Canonically, GABA-ergic inhibition curtails neuronal activity. This effect occurs via either hyperpolarization or shunting, depending on the chloride driving force, the resting membrane potential, and the action potential threshold at the time the impulse arrives. GABA is depolarizing in the earliest developing neurons that have not yet expressed specific membrane transporters to establish the usual chloride gradient (Ganguly et al., 2001; Ben-Ari et al., 2007; Ben-Ari, 2015). Because the neonate brain contains neurons at many different stages of development, anesthetics potentiating GABA-mediated currents could be excitatory in some neurons.
At clinical doses, most anesthetics act as positive allosteric modulators, increasing channel function by binding to protein cavities remote from the ligand binding site and causing conformational changes in structure that increase and prolong the response to GABA. Several interaction sites for volatile agents on the $\mathrm{GABA}_{\mathrm{A}} \mathrm{R}$ have been identified through mutagenic and biophysical experiments (Franks, 2006). Similarly, sites for intravenous agents have been identified (Miller and Aricescu, 2014; Weiser et al., 2014). On the intracellular face of the receptor, each subunit contains a small cytoplasmic loop between the first and second transmembrane domains and a larger cytoplasmic loop between the third and fourth transmembrane domain. This larger loop domain has the largest sequence variability between subtypes (Olsen and Sieghart, 2008), and contains several sites for protein-protein interactions. This intracellular loop is the 
main site for regulatory control of membrane trafficking by intracellular signaling pathways.

Receptor sequence heterogeneity is well studied as a source of subtle biophysical properties that lead to pharmacologic specificity for various endogenous and exogenous substances, including anesthetic agents. Recombinant studies demonstrate that the $\alpha$ subunit contributes to biophysical difference in GABA sensitivity, as heterologously expressed $\alpha 1 \beta 2 \gamma 2$ receptors show a lower affinity than $\alpha 4 \beta 2 \gamma 2$ (Jia et al., 2005). In most of the brain, intrasynaptic receptors contain $\alpha 1-3$ whereas extra-synaptic receptors contain $\alpha 4-6$ (Farrant and Nusser, 2005). Although all of these subunits are subject to allosteric modulation by anesthetic agents (with the notable exception of $\rho$ ), the sensitivity to anesthetics is not equal, and the extrasynaptic receptors are comparatively sensitive to modulation by anesthetics (Bonin and Orser, 2008).

\section{INTRASYNAPTIC AND EXTRA-SYNAPTIC GABA ${ }_{A} R$ POPULATIONS GENERATE PHASIC AND TONIC CURRENT}

GABA-ergic neurotransmission evokes two distinct forms of inhibitory currents. The basis for these two types of currents lies within receptor subunit composition and subcellular location. Phasic currents are primarily mediated by low-affinity intrasynaptic receptors, which generate brief and quickly desensitizing inhibitory post-synaptic currents (IPSCs) in response to synaptic neurotransmission (Mody and Pearce, 2004). Intrasynaptic receptor clustering is based on the construction of the GABAergic synapse, which is made of a post-synaptic density of several proteins organized opposite to the presynaptic terminal (Tretter et al., 2012). Intrasynaptic receptors are typically are made of large clusters of $\alpha 1, \alpha 2$, or $\alpha 3$ containing receptors anchored to the post-synaptic cytoskeleton by the scaffold protein gephyrin. Inside the synapse, these receptor clusters are transiently exposed to high $(\sim \mathrm{mM})$ concentrations of GABA from synaptic vesicular release, and generate phasic currents that terminate after GABA is cleared from the synapse (Stell and Mody, 2002). Even before clearance by glial or neuronal pumps, phasic currents rapidly desensitize generating the characteristic decayed shape of the ISPC.

Tonic currents are mediated by extra-synaptically located receptors, which generate persistent conductances in response to smaller $(\sim n M-\mu M)$ amounts of GABA existing in the intercellular space (Stell and Mody, 2002). The extra-synaptic receptors have a higher affinity for GABA and ideal for detection of small amounts of neurotransmitter. Additionally, these receptors exhibit little or no accommodation to saturating concentrations of GABA, a phenomenon known as desensitization. The GABA that evokes tonic current is thought to arise from two overlapping sources, ambient and spill-over GABA. Ambient GABA describes the minute amount preexisting in the extracellular space. Measurements from in vivo microdialysis suggest peri-synaptic GABA is between $\approx 30-300 \mathrm{nM}$, depending on brain region (Lerma et al., 1986; Tossman et al., 1986). Notably, GABA levels can change with physiological and behavioral states (de Groote and Linthorst, 2007). Spill-over GABA is released by synaptic transmission and diffuses away to have paracrine action on remote receptors, e.g., on other neurons. These terms have conceptual overlap and do not demarcate two types of GABA, but rather distinguish effects in spatiotemporal relation to synaptic transmission. High levels of phasic inhibition can drive spillover and raise local ambient GABA. For example, an increase in inhibitory activity can encourage sleepiness in part due to the accumulation of ambient GABA.

Comparatively, tonic and phasic inhibitory currents generate different effects on neuronal excitability and consequent inhibitory/excitatory signaling dynamics (Mody and Pearce, 2004). Functionally, phasic GABA currents decrease the instantaneous probability of action potential firing. In contrast, tonic currents cause a more persistent ongoing inhibition or hyperpolarization that is not temporally discrete. Because tonic current decreases membrane resistance, hypothetically the behavior of more actively firing neuron would be more sensitive to tonic inhibition than a less actively firing one. How these conductances ultimately affect individual neurophysiological process depends on cell-type specific intrinsic properties as well as circuit-specific properties. For example, interneuron spiking behavior changes dramatically with the addition of tonic GABA inhibitory input (Pavlov et al., 2014) in a bidirectional manner related to intrinsic cellular properties. Subcellular innervation patterns onto target neurons (e.g., axo-axonic vs. axo-somatic vs. axo-dendritic) would also critically determine post-synaptic effect. Further complicating a straightforward interpretation of anesthetic effects as a function of GABAergic modulation is the widespread expression of $\mathrm{GABA}_{\mathrm{A}}$ Rs. An inhibitory input onto a target neurons could be modulated at the post-synaptic level (anesthetic enhancement of post-synaptic $\mathrm{GABA}_{\mathrm{A}} \mathrm{Rs}$ ), or at the pre-synaptic level (anesthetic enhancement of interneuron $\mathrm{GABA}_{\mathrm{A}} \mathrm{Rs}$ and depressed output and disinhibiting of the target neuron). In neuroscience at large, recent significant technical advances in methods of isolating cell-type specific actions via genetically select identification and activation have revolutionized empirical characterization of neural circuits (Murphey et al., 2014). The application of similar strategies to the study of anesthetic mechanisms could clarify with greater precision how anesthetics affect inhibitory actions within select neural circuits.

Finally, phasic and tonic conductances also shape emergent neural network properties such as oscillations (Mann and Mody, 2010). The temporal dynamics of phasic inhibition are important because synchronizing population activity into slow oscillatory waves requires precise timing of inhibitory input. Tonic current is important in rhythmogenesis as an input counteracting tonic excitation, as well as factor in the activation of hyperpolarizationgated conductances. 


\section{SUBUNIT COMPOSITION AND SENSITIVITY TO ANESTHESIA-RELATED DRUGS}

At clinically used doses, GABA-ergic anesthetics generally potentiate phasic currents by prolonging IPSC duration, and tonic currents by increasing the amplitude and charge transfer. Pharmacologic substances do not affect tonic and phasic conductances in the same way (Bieda et al., 2009). An enhanced sensitivity to GABA-ergic anesthetic drugs is a common feature of extra-synaptic receptors (Bonin and Orser, 2008). In hippocampal pyramidal excitatory neurons, low concentrations (25 $\mu \mathrm{M}$ ) of isoflurane enhance the $\alpha 5$ mediated tonic but not phasic current (Caraiscos et al., 2004b). In the same experiments, $100 \mu \mathrm{M}$ is the minimal dose to enhance IPSCs. These reactions to sub-anesthetic doses may explain why low doses of our anesthetics produce a sedation phenotype. Similarly, direct activation-low doses of isoflurane will also directly activate $\alpha 4$ s, whereas only high doses can directly activate $\alpha 1$ (Raines et al., 2003). For reference a typical concentration of isoflurane which might mediate unconsciousness clinically is $250-300 \mu \mathrm{M}$ (Hemmings and Egan, 2013).

The behavioral responses of transgenic mice with mutated extra-synaptic subunits suggest that disabling the receptors mediating tonic current is sufficient to abolish specific elements of anesthesia. For example, deleting the $\alpha 4$ subunit significantly reduces the effect of isoflurane on amnesia (context-dependent fear learning) with no effect on hypnosis or immobility (Rau et al., 2009). The potential importance of this is that intraoperative amnesia likely happens because low sub-anesthetic doses of isoflurane are sufficient to impair learning and memory by increasing $\alpha 4 \beta x \delta$ tonic current in the dentate gyrus, so changes in $\alpha 4$ surface expression could affect amnesia without affecting the other anesthetic endpoints that are more salient during operation.

Benzodiazepines (e.g., midazolam) allosterically potentiate receptors containing the $\gamma 2$ subunit, with sensitivity determined by the $\alpha$ subunit (Jenkins et al., 2001). Conversely, the $\delta$ containing receptors which mediate tonic current are insensitive to benzodiazepines but very sensitive to allosteric enhancement by neurosteroids (Mody and Pearce, 2004).

Barbiturates (e.g., thiopental) also allosterically potentiate $\mathrm{GABA}_{\mathrm{A}} \mathrm{Rs}$ at clinically delivered doses. Evidence suggest sites of action within $\alpha$ and $\beta$ subunits, and potentially elsewhere. Hippocampal CA1 phasic currents appear to be more sensitive than tonic to potentiation by thiopental (Bieda et al., 2009), although significant effects were seen on both. The largely cerebellar $\alpha 6$ extrasynaptic receptor has a uniquely high sensitivity to pentobarbital (Drafts and Fisher, 2006), perhaps underlying anticonvulsant and ataxic properties, although potentiating effects can also be seen on $\alpha 4 \beta 2 \gamma 2$ and $\alpha 4 \beta 2 \delta$ (Akk et al., 2004). Of historical note, the barbiturates were once the mainstay class of anesthetic agents. With the exception of thiopental, they were largely replaced for routine anesthesia due to a range of undesirable side-effects including the potentially dangerous overlap between anesthetic range and lethal doses.
However, they remain in use for veterinary euthanasia (e.g., for biomedical research animals) and for capital punishment via lethal injection.

\section{SPECIFIC SUBUNIT COMPOSITIONS AS NEUROANATOMICAL TARGETS OF ANESTHESIA}

The exact receptor subtypes that underlie tonic and phasic currents are particular to brain region. Here we summarize receptor subtype distribution, and for each receptor population its hypothesized role in anesthesia. For this review, we focus more on regions of the brain heavily involved in consciousness and memory, to reflect clinical concerns about depth of anesthesia and lingering effects on attention and memory observed.

\section{The Hippocampus}

Traditionally associated with the formation of memories, the hippocampus has been studied for decades in order to understand anesthetic mechanisms in a convenient, standardized laboratory model, specifically the acutely prepared rodent ex vivo brain slice. From this paradigm, we have considerable knowledge of cellular substrates that mediate anesthetic amnesia and potentially the long-lasting effects of anesthetics on memory function. Within hippocampus CA1-3 subfield pyramidal neurons, phasic current is mediated by mostly $\alpha 1 \beta 2 / 3 \gamma 2$ intrasynaptic receptors (Sperk et al., 1997; Caraiscos et al., 2004a), and tonic current by $\alpha 5 \beta 3 \gamma 2$ extrasynaptic receptors (Bonin et al., 2007). Within the dentate gyrus (DG), which controls afferent input into the CA regions, principal granular cell neurons phasic current is mediated by $\alpha 1 \beta 2 / 3 \gamma 2$ intrasynaptic receptors, whereas tonic current is mediated instead largely by $\alpha 4 \beta x \delta$ extrasynaptic receptors, with some additional tonic conductance likely from $\alpha 5 \beta 3 \gamma 2$ s as well (Herd et al., 2008). The amnestic effects of alcohol are thought to be a consequence of $\delta$-subunit mediated sensitivity of these $\alpha 4 \beta x \delta$ receptors to alcohol (Mody et al., 2007).

The difference between tonic current receptor expression within these subfields may be related to intrinsic differences between CA3/CA1 pyramidal cells and DG granule cells. The DG is located at the entry of entorhinal excitatory projections into the hippocampus, and hypothesized to have an important role in "gating" or filtering the excitatory input into the dorsal CA subfields, which themselves are mostly excitatory neurons with more active phenotypes. In electrophysiologic study DG granule cells are described as a low-excitability reluctantly firing phenotype- defined by the absence of action potentials even in response to high-intensity current injection- owing partially to the strong tonic inhibitory conductances mediated by $\alpha 4 \beta x \delta$ extra-synaptic receptors and a more hyperpolarized resting membrane potentials compared to CA neurons (Coulter and Carlson, 2007). This strong tonic inhibition is thought to be important for spatial information processing and memory information because a high firing threshold would ensure that only small, selective population is activated within a single context, constraining inappropriate signal transfer into the hippocampus. During spatial navigation, DG granule cells fire 
sparsely, with greater place-field specificity than CA3 neurons (Jung and McNaughton, 1993; Senzai and Buzsaki, 2017). Based on these properties, the prevailing theoretical function for the DG as a computational entity is pattern separation, or the ability to de-correlate similar inputs and generate dissimilar outputs, which would be essential to create discrete neural representations (Knierim and Neunuebel, 2016). Moreover, limiting excitation has an important protective feature for "gating" the hippocampal network, which is laden with recurrent connections and prone to epileptogenesis (Lothman et al., 1992; Peng et al., 2004). The importance of tonic inhibition for creating a low-excitability cellular phenotype can be further observed in an array of epileptogenic phenotypes where extrasynaptic $\mathrm{GABA}_{\mathrm{A}} \mathrm{R}$ receptor-mediated tonic inhibition is compromised (Maguire et al., 2005; Ferando and Mody, 2012; Li et al., 2013).

Within hippocampal interneurons, the effect of modulating tonic inhibition is cell-type specific. For example, almost all fast spiking parvalbumin-expressing interneurons in DG express $\alpha 4 \beta 3 \delta \mathrm{GABA}_{\mathrm{A}} \mathrm{R}$-mediated tonic currents, whereas a minority of somatostatin-expressing interneurons and no calbindin or calretinin-expressing do (Milenkovic et al., 2013). This illustrates a general principal that specialized interneuron species have characteristic firing patterns based on particular calcium-binding protein expression (e.g., parvalbumin and calbindin) and $\mathrm{GABA}_{\mathrm{A}} \mathrm{R}$ receptor subunit expression. Unsurprisingly given the importance of this interneuron subpopulation in rhythmogenesis, deletion of the $\beta 3$ extra-synaptic receptor subunit generates abnormalities in hippocampal theta and gamma oscillations (Hentschke et al., 2009). Tonic current-mediated changes in gamma oscillations can be observed as an effect of ovarian-cycle linked changes in $\alpha 4 \beta 3 \delta$ expression, perhaps underlying peri-menstrual cognitive side-effects (Barth et al., 2014).

\section{The Thalamus}

Somatosensory information from the external world is integrated in specific thalamic nuclei before complex processing by the cortex. Thus, thalamic neural processes are uniquely important in the control and transformation of conscious experiences, perhaps like a dynamic gate (Steriade, 2000). Anesthetic-induced depression of neuronal activity in thalamic nuclei and subsequent suppression of the thalamo-cortical circuit are thought to underlie loss of consciousness and unresponsiveness to sensory input.

During awake states, subcortical arousal areas depolarize thalamic neurons, which mediate the integration of information in important cortical areas such as the hippocampus and prefrontal cortex (Llinas and Steriade, 2006). During states of impaired consciousness such as drowsiness, anesthesia, or slowwave sleep, hyperpolarized thalamic relay neurons hyperpolarize and generate slow oscillations that entrain cortical neurons. Typically two slow rhythms result and dominate the non-REM sleep EEG, delta waves and alpha waves. During anesthesia, EEG recordings of fully anesthetized patients typically show either strong slow wave activity or "burst suppression" spectral patterns where high frequency activity is interleaved with periods of very slow or flat-lined "isoelectric" electrical activity (Brown et al., 2010; Chander et al., 2014). These isoelectric EEG epochs, characteristic of comatose brains, are never found in natural sleep patterns and thought to be an effect of very deep anesthesia. The predominant understanding is that these patterns are generated by the effect of anesthetics on extra-synaptic receptor mediated tonic currents in the ventral basal thalamic neurons. These regions are enriched in $\alpha 4 \beta 2 \delta$ extra-synaptic receptors. In vitro, this subtype is very sensitive to isoflurane (Jia et al., 2008). In vivo, firing of thalamo-cortical relay neurons is strongly depressed by isoflurane in a GABA dependent manner (Jia et al., 2005).

The exact contributions of receptor subtypes have been mostly tested with respect to naturally occurring (e.g., sleep) induced oscillatory behaviors, and implications for anesthetic-specific oscillations are currently limited by assumed similarities and a few insightful studies (Steriade, 2000). Evidence currently suggests that thalamocortical oscillations are entrained by phasic inhibition, but largely depend on tonic inhibition to occur (Rovo et al., 2014). Thalamic removal of $\gamma 2$, causing cell surface depletion of local intrasynaptic receptors, did not abolish slow thalamocortical oscillations or sleep spindles but did alter single-neuron burst firing. Because thalamocortical network activity is essential to consciousness, this would suggest that alterations in $\mathrm{GABA}_{\mathrm{A}} \mathrm{R}$ surface expression affect sensitivity to hypnotics.

\section{The Cortex}

The cortex is most associated with anesthetic hypnosis. In most layers the extra-synaptic receptor is $\alpha 5 \beta 3 \gamma 2$, but in layer $2 / 3$ extra-synaptic receptors demonstrate the $\alpha 4 \beta 2 \delta$ configuration. These generalizations about cortical layers should be taken with consideration to the region, because the stratification of cortical layers can have a specific functional role in different processes. Cortical layers $2 / 3$ receive information from other cortical areas. Slow oscillations like delta waves are only detected on EEG when all layers II/III and V are synchronized with thalamic inputs, and otherwise the beta frequency activity dominates (Harrison, 2007). During wakefulness, alpha and beta emanating most strongly from the posterior of the brain, namely the occipital lobe, predominate cortical EEG when the eyes are closed. During induction, alpha decreases globally but there also is a spatial shift or "anteriorization" in alpha power, meaning that it is now strongest from the frontal cortex (Brown et al., 2010; Mashour, 2014). This effect is also thought to be based on the expression of anesthetic sensitivity of $\alpha 4 \beta 2 \delta$ receptors on ventrobasal thalamus neurons. These neurons project to the frontal cortex, entraining their activity. In contrast, the posteriorly projecting thalamic nuclei do not express these receptors. This model is supported by functional MRI measurements taken during propofol anesthesia. Resting state network analysis suggests that disconnect between networks within the frontal cortex is part of loss of consciousness by propofol (Guldenmund et al., 2016).

Phasic and tonic currents mediate distinct temporal modulation of single-cell neuronal activity, and contribute differently to the microscopic conductances that generate patterns of neuronal population activity empirically observed from human patients, such as evoked field potential or EEG recordings. A straightforward example can be made of 
the receptors mediating cortical local inhibition. The most superficial layer of cortex is largely populated by the apical dendrites of layer 5 pyramidal excitatory neurons, and their dendritic local field potentials predominate the forebrain scalp EEG signal (Brown et al., 2010). Here, intrasynaptic $\alpha 1 \beta \times \gamma 2$ receptors mediate synaptic inhibition from local interneurons, whereas the extra-synaptic $\alpha 5 \beta 3 \gamma 2$ receptors mediate tonic inhibition of cortical neuron activity (Ali and Thomson, 2008). Judging the comparative contribution to the EEG signal is less straightforward; because the $\alpha 5 \beta 3 \gamma 2$ receptors are heavily expressed in the distal dendrites whereas the $\alpha 1 \beta \mathrm{x} \gamma 2$ receptors are somatically expressed (Sur et al., 1999b), the extra-synaptic receptors are more superficial and may arguably better represented in the scalp EEG. These distinctions may be important for interpreting the effects of subtype-specific pharmacology. Of course, these various inhibitory inputs converge upon synaptic integration, and ultimately dendritic field potentials are a biased reflection of cortical activity.

Sedation is also thought to arise from anesthetic effects on cortical systems. Although qualitatively akin to a mild hypnosis, there is evidence for molecular targets that are more specific for sedation. For example, etomidate-mediated sedation but not hypnosis is lost in the $\beta 2(\mathrm{~N} 265 \mathrm{~S})$ transgenic mouse, and the action of the benzodiazepine diazepam at $\alpha 1$ His 101 provides sedation but not hypnosis (Bonin and Orser, 2008).

\section{Subcortical Arousal Centers}

Wakefulness and somnolence are governed by a system of neuromodulatory projection neurons that originate in several subcortical nuclei that widely innervate the brain. Rationally, anesthetic action on these regions is a clear and direct mechanism for loss of consciousness. However, predicting the contribution of these subcortical arousal centers to anesthesia is complicated by the involvement of these systems in sleep, as well as redundant arousal circuitry. When, $\mathrm{GABA}_{\mathrm{A}} \mathrm{R}$ current sensitivity to propofol was tested in three arousal centers targeted by natural sleep pathways using the $\beta 3(\mathrm{~N} 265 \mathrm{M})$ transgenic mouse, the perifornicate and tuberomamillary nucleus (TMN) but not the locus coeruleus were affected (Zecharia et al., 2009). TMN is in hypothalamus, projects the arousal neurotransmitter histamine into cortex to generate wakefulness. In anesthesia, propofol enhancement of GABA in TMN depresses histamine release into the cortex (Zecharia and Franks, 2009). Excellent and thorough reviews of subcortical areas involved in arousal and their influence on sleep and anesthesia can be found elsewhere (Brown et al., 2011).

\section{Spinal Cord and Peripheral Nervous System}

Early seminal experiments demonstrated that distinct anesthetic targets within the brain and spinal cord mediate distinct mechanisms for hypnosis vs. analgesia, respectively (Antognini and Schwartz, 1993; Antognini and Carstens, 1998; Antognini et al., 1998). The classical molecular sites for anesthetic analgesia, or blockade of nociception, lie in the spinal cord dorsal horn, where primary afferents innervating somatic and visceral tissue first synapse onto CNS neurons to relay sensory information. Anesthetic potentiation of $\mathrm{GABA}_{\mathrm{A}} \mathrm{Rs}$ on pain-mediating nociceptive afferent presynaptic terminals as well as $\mathrm{GABA}_{\mathrm{A}} \mathrm{Rs}$ on post-synaptic neurons largely in lamina II/substantia gelatinosa contribute to blunted relay of sensory information. Evidence suggests these are largely $\alpha 2 / 3 \beta 2 / 3 \gamma 2$ intrasynaptic subtypes (Bohlhalter et al., 1996). Anesthetic actions on $\mathrm{GABA}_{\mathrm{A}} \mathrm{Rs}$ within the ventral horn (intrinsic neurons and motor neurons) contribute to anesthetic immobility and muscle relaxation, although during surgery adjunct drugs acting directly on the neuromuscular junction are typically given to reinforce these effects.

\section{GABA $_{A} R$ SURFACE EXPRESSION IS CONTROLLED BY INTRACELLULAR TRAFFICKING}

The strength of inhibitory currents, tonic or phasic, depends on the number of receptors expressed on the neuronal cell surface. This number is dynamically maintained because $\mathrm{GABA}_{\mathrm{A}}$ Rs undergo controlled rates of endocytosis, exocytosis, and degradation- in effect constantly recycling between the surface and the cytoplasm. These events are coordinated by a myriad of effector and regulatory proteins, themselves controlled by second messengers signaling events. Perturbations to all of these steps can potentially alter GABAergic signaling, e.g., an increase in surface expression and current can arise from increased rates of exocytosis, reduced endocytosis, or decreased degradation. Given that changes in surface expression can be observed in vitro on the time course of $15-30 \mathrm{~min}$, it is conceivable that routine anesthesia care has major influence on the dynamics of membrane surface expression. A basic review of fundamental trafficking mechanisms is presented first, before a discussion of mechanisms for pharmacologic and activity based changes in $\mathrm{GABA}_{\mathrm{A}} \mathrm{R}$ surface expression.

\section{Receptor Biosynthesis, Exocytosis, and Subcellular Localization}

$\mathrm{GABA}_{\mathrm{A}}$ receptor subunits are synthesized in the endoplasmic reticulum (ER). Correctly oligomerized channels under post-translational processing within the Golgi apparatus and then actively exported to the cell surface and inserted into the plasma membrane by exocytosis (Luscher et al., 2011). Imaging and biochemical assays suggest that receptor insertion occurs extra-synaptically (Bogdanov et al., 2006), and intrasynaptic receptors undergo additional targeting to the post-synaptic density via lateral diffusion (Bannai et al., 2009). Kinetic studies suggest that movement into the synapse happens quickly, as the ratio of synaptic/extra-synaptic $\beta 3 \mathrm{~s}$ increases significantly within 15 min (Bogdanov et al., 2006). Synaptic confinement involves direct interaction gephyrin (Jacob et al., 2005), the cytoskeletal-bound post-synaptic scaffolding protein of inhibitory synapses, through binding sites on $\alpha 1, \alpha 2, \alpha 3, \beta 2$, and $\beta 3$ subunit large cytoplasmic loops (Tretter et al., 2012). 
Keeping extra-synaptic receptors in place is less understood. The $\alpha 5 \beta 3 \gamma 2$ receptors affix to the cytoskeleton in extra-synaptic clusters by the scaffolding protein radixin. Their extra-synaptic confinement is not static, and dissociation from radixin and into synapses has been identified as a novel mechanism means of synaptic strengthening (Hausrat et al., 2015). Within synapses, $\alpha 5 \beta 3 \gamma 2$ receptors mediate a slowly decaying component of IPSCs through transient interactions with gephyrin (Brady and Jacob, 2015). GABA $_{A} R$ exchange between intrasynaptic and extra-synaptic sites is under active investigation as a potentially important form of inhibitory plasticity (Triller and Choquet, 2005). The extra-synaptic location of $\alpha 4 \beta \mathrm{x} \delta$ receptors is attributed to absence of a gephyrin binding site within the $\alpha 4$ protein sequence, as an extra-synaptic scaffolding protein for $\alpha 4 \beta x \delta$ has not been identified. In general, structural and regulatory elements for extra-synaptic receptor densities have not been well characterized. Because of their unique pharmacological role in anesthetic-hyperpolarization, understanding the mechanics of extra-synaptic receptor movement within the cell and its surface is a critical knowledge gap in anesthetic mechanisms.

\section{ENDOCYTOSIS AND POST-ENDOCYTOTIC SORTING: RECYCLING VS. DEGRADATION}

$\mathrm{GABA}_{\mathrm{A}} \mathrm{Rs}$ are constantly removed from the cell surface via clathrin-mediated endocytosis, which is orchestrated by complex sequences of proteins interactions all critically dependant on subunit-specific endocytotic regulatory site. These physical interactions are subject to modulation by post-translational modifications (especially phosphorylation), and aberrations can dramatically affect surface expression. The details are well-summarized elsewhere (Nakamura et al., 2015). Because these regulatory processes depend on specific protein residues, anatomical and behavioral phenotypes can be observed in a subunit-specific manner. For example, transgenic knock-in mice expressing $\gamma 2$ (Y265/7F) phosphomimetic receptors, which lack $\gamma 2$ Y265/7 mediated endocytosis, have increased $\gamma 2$ cell surface expression, larger inhibitory synapses, and impaired spatial memory (Kretschmannova et al., 2013). Notably, this trafficking phenotype engenders an abnormal responses to anesthesia, as female $\gamma 2(\mathrm{Y} 256 / 7 \mathrm{~F})$ mice are more sensitive to the amnestic and hypnotic effects of propofol. The basis is likely the higher measurements of $\alpha 4 \beta \mathrm{x} \delta$ in the thalamus and DG as a result of compensatory changes in gene expression and surface trafficking that is gender-sensitive. Induced changes endocytotic regulation may have a rapid effect on surface expression because of the relatively quick rates of constitutive intrasynaptic receptor endocytosis. Biochemical rate-measurements suggest that intrasynaptic receptor constitutive endocytosis occurs rapidly, with approximately $20-25 \%$ of surface receptor $\beta 3$ subunits internalizing by $30 \mathrm{~min}$ in neuron cultures (Kittler et al., 2004). Other groups have shown significant internalized $\gamma 2$ protein after 15 min (Joshi and Kapur, 2009).
Likewise, specific endocytotic mechanisms for the $\alpha 4 \beta x \delta$ receptors mediating tonic current are mediated through unique sequences on the $\delta$ subunit (Gonzalez et al., 2012). Kinetically, constitutive endocytosis of $\delta$-containing receptors appears to occur more slowly than intrasynaptic receptors. The surface halflife of $\delta$ subunits is $103-171 \mathrm{~min}$ depending on the measurement method, immunostaining in culture or slice biotinylation in organotypic hippocampal slices, respectively (Joshi and Kapur, 2009). However, ethanol-evoked endocytosis of $\alpha 4 \beta \mathrm{x} \delta$ happens more quickly, as significantly diminished surface expression can be measured within 15 min (Gonzalez et al., 2012). Given the role of $\alpha 4 \beta x \delta$-mediated tonic current in thalamocortical and hippocampal circuits underlying anesthetic hypnosis and amnesia, $\alpha 4 \beta \mathrm{x} \delta$ trafficking changes have a direct bearing on the behavioral response to anesthesia. For example, latency to loss of righting reflex (metric for sensitivity to anesthetic hypnosis) increases 12 and $24 \mathrm{~h}$ following ethanol intoxication, suggesting a desensitization to isoflurane (Liang et al., 2007).

Once internalized, $\mathrm{GABA}_{\mathrm{A}} \mathrm{R}$ containing endosomes are sorted between recycling endosomes or late endosomes destined for lysosomal degradation. Recycled receptor endosomes reside transiently beneath the cell surface. Intracellular $\mathrm{GABA}_{\mathrm{A}} \mathrm{Rs}$ residing near gephyrin underneath the synapse have been identified, presumably forming receptor reservoirs that can be rapidly mobilized to mediate short-term inhibitory synaptic plasticity (van Rijnsoever et al., 2005).

Ubiquitinylated receptors can also be targeted for degradation within lysosomes, acidic organelles which enzymatically digest the proteins inside. Again, this process appears to happen relatively quickly, as rate studies in cultured neurons suggested that $30 \%$ of neuronal $\mathrm{GABA}_{\mathrm{A}}$ Rs degraded over the course of $6 \mathrm{~h}$ (Kittler et al., 2004). Overall, it is clear that GABA $\mathrm{R}$ intracellular movement is a complicated dynamic process with rapid kinetics, and very subtle changes in protein signaling and have the capacity to change surface expression and phenotype very quickly.

\section{ANESTHETICS AND GABA ${ }_{A} R$ SURFACE EXPRESSION}

Recent research has shown that anesthesia itself may cause changes to the surface expression of $\mathrm{GABA}_{\mathrm{A}} \mathrm{Rs}$ and other ion channels that control neurological function. At present, these changes appear to be mediated by the effect of anesthetics on the intracellular signaling pathways that control trafficking. Propofol was demonstrated to increase $\beta 3$ subunit surface expression in hippocampal brain and primary cultures within 15, 30, and 60 min of exposure (Li et al., 2015). The underlying mechanism is PKC-mediated phosphorylation of $\beta 3$ at the AP-2 binding domain. Immunoprecipitation of $\beta 3$ from hippocampal lysates show a depressed association with AP-2 subunit $\beta$-adaptin, suggesting diminished recruitment of the entire AP-2 complex. Surface expression of GluR1, a subunit of AMPA receptors which are also trafficked using AP-2 and clathrin-mediated endocytosis, was not significantly affected, suggesting that propofol is not impairing general endocytotic mechanisms. Activated PKC $\varepsilon$ is increased at these timepoints. $\mathrm{PKC} \varepsilon$ kinase activity on $\beta 3$ 
receptors measured with hippocampal lysate and recombinant PKC shows increased $\beta 3$ phosphorylation. The change in surface expression and decrease in AP-2 subunit binding are blocked with PKCE inhibitor (Li et al., 2015). Functionally, propofol causes an increase in evoked and miniature IPSC amplitude that can be partially reversed with PKCE inhibitor. Post-translational modification of channel kinetics by PKC and allosteric enhancement of channel function by propofol likely contribute to this effect, but the effect of the inhibitor suggests that ultimately propofol is creating a temporary sensitization of GABAergic transmission through PKC $\varepsilon$-dependant mechanisms. Similarly, a temporary increase in $\alpha 5$ surface expression has been associated with etomidate administration (Zurek et al., 2014). This increase appears to be in part responsible for post-anesthesia memory impairment. The expression levels return to normal in 2 weeks.

Several networks of second messengers and signaling protein regulators that control or influence the subcellular movement of $\mathrm{GABA}_{\mathrm{A}}$ Rs are also potentially sensitive to anesthetics. The interactions of these pathways with drugs commonly used in anesthesia are just being recognized and remain an area of active investigation. Here, we briefly introduce canonical pathways known to impact $\mathrm{GABA}_{\mathrm{A}} \mathrm{R}$ surface expression, describe the basis for anesthetic-sensitivity, and speculate hypothetical impact on $\mathrm{GABA}_{\mathrm{A}} \mathrm{R}$ surface expression.

\section{Calcium and IP3R Pathway}

Calcium is one of the most important intracellular second messengers, and isoflurane itself will raise intracellular calcium by directly activating the inositol 3-phosphate receptor (IP3R) channel resulting in the release of stored calcium into the cytosol (Wei and Xie, 2009). Several proteins regulating of $\mathrm{GABA}_{\mathrm{A}} \mathrm{R}$ surface expression are calcium-dependent, including PKC which controls trafficking of several subunits through many phosphorylation sites (Abramian et al., 2010; Nakamura et al., 2015).

\section{PKC}

Propofol itself can activate and allosterically enhance PKCE, a calcium-independent isozyme. In vitro studies of the direct interaction between propofol and the regulatory domain of PKC promotes autophosphorylation at Ser729, a final step in initiating and maintaining enzyme activation. In addition to the propofol-mediated surface $\beta 3$ discussed earlier (Li et al., 2015), the activation of $\mathrm{PKC} \varepsilon$ by propofol also leads to downstream activation of the transcription factor target CREB (Wickley et al., 2009). The transcriptional control of $\alpha 1$ surface expression by PKC/CREB signaling has already been demonstrated ( $\mathrm{Hu}$ et al., 2008), but not testing following propofol.

\section{Rho Kinase/ROCK Signaling}

Propofol has been shown to interfere with neuronal development by causing neurite retraction through the Rho kinase/ROCK signaling pathway (Bjornstrom et al., 2014), through effects on PKC $\varepsilon$. This interaction may be significant for surface expression because Rho/ROCK signaling regulates $\alpha 5 \beta 3 \gamma 2$ extra-synaptic localization by controlling $\alpha 5$-radixin binding, which in turn affects synaptic $\alpha 5 \beta 3 \gamma 2$ levels (Hausrat et al., 2015).

\section{Inflammatory Signaling}

The interaction between volatile anesthetics and the endogenous neuroimmune system is under great scrutiny as a factor in the development of cognitive impairments following surgery, such as post-operative delirium and post-operative cognitive dysfunction (Vutskits and Xie, 2016). One important line of reason is the relationship between inflammation and increased extra-synaptic $\mathrm{GABA}_{\mathrm{A}} \mathrm{Rs}$ surface expression and associated memory impairments. Application of the inflammatory cytokine IL-1 $\beta$ to hippocampal neurons increases $\alpha 5 \beta 2 \gamma 2$ surface expression, increasing both tonic current and its potentiation by anesthetics (Wang et al., 2012; Avramescu et al., 2016). Mice treated with lipopolysaccharide injections, which models sepsis by stimulating the innate immune system, show potentiated hypnosis and ataxia from isoflurane and etomidate (Avramescu et al., 2016). Depressions in spatial memory and fear based learning, and long-term potentiation seen in these animals appears to be reversible with $\alpha 5$ receptor antagonist, $\alpha 5$ subunit deletion, or blockade of p38 mitogen-activated protein kinase signaling (Wang et al., 2012). Unsurprising, septic patients display anesthetic hypersensitivity (Monk et al., 2005). We speculate that blockade of inflammatory signaling in the brain, either that induced by volatile anesthetics themselves and/or those induced by systemic inflammation, may protect against post-operative neurocognitive impairments partially by preventing the development of deleterious changes in $\mathrm{GABA}_{\mathrm{A}} \mathrm{R}$ surface expression.

\section{SUMMARY}

The perioperative experience is an opportunity for profound dynamic changes in $\mathrm{GABA}_{\mathrm{A}} \mathrm{R}$ expression. Despite specific knowledge regarding individual subunit compositions subcellular localization, regional anatomy, and pharmacological attributes, we still lack understanding of the contribution of these specifics to intra- and post-operative consequences. Off-target effects on receptor trafficking subtype expression can impart neurophysiologic differences that likely influence the heterogeneity in behavioral endpoints of anesthesia, and variability in cognitive recovery trajectories following emergence. Because of the profound differences in GABA-signaling between developing and mature neurons - a focus on experiments using mature neurons should be emphasized, despite the increased technical challenges of working with older neurons in vitro. Future research avenues include studies using combined living cell microscopy and photolabeling that can help detect important changes in expression levels on relevant time scales.

General anesthetics are invaluable and unique among medicines because of their capacity for controlled manipulation of consciousness. Although substantial work has been done to characterize the effect of anesthetic agents on biophysical 
function of $\mathrm{GABA}_{\mathrm{A}}$ Rs and the resultant effect on global patterns of brain activity, much less is known about the long-term consequences on neurological function. Experimental studies increasingly show that anesthetic agents have the potential to induce persistent changes in neurophysiology, which has serious implications for basic and clinical science alike. A comprehensive understanding of these processes will be necessary for predicting how persistent adverse effects in neurological function arise and determining what factors underlie resilience to the effects of anesthetics.

\section{AUTHOR CONTRIBUTIONS}

IS performed the literature search, organized the theme, wrote the first draft, and constructed the table. EB and PG added

\section{REFERENCES}

Abramian, A. M., Comenencia-Ortiz, E., Modgil, A., Vien, T. N., Nakamura, Y., Moore, Y. E., et al. (2014). Neurosteroids promote phosphorylation and membrane insertion of extrasynaptic GABAA receptors. Proc. Natl. Acad. Sci. U.S.A. 111, 7132-7137. doi: 10.1073/pnas.1403285111

Abramian, A. M., Comenencia-Ortiz, E., Vithlani, M., Tretter, E. V., Sieghart, W., Davies, P. A., et al. (2010). Protein kinase C phosphorylation regulates membrane insertion of GABAA receptor subtypes that mediate tonic inhibition. J. Biol. Chem. 285, 41795-41805. doi: 10.1074/jbc.M110.149229

Akk, G., Bracamontes, J., and Steinbach, J. H. (2004). Activation of GABA(A) receptors containing the alpha4 subunit by GABA and pentobarbital. J. Physiol. 556(Pt 2), 387-399. doi: 10.1113/jphysiol.2003.058230

Ali, A. B., and Thomson, A. M. (2008). Synaptic alpha 5 subunit-containing GABAA receptors mediate IPSPs elicited by dendrite-preferring cells in rat neocortex. Cereb. Cortex 18, 1260-1271. doi: 10.1093/cercor/bhm160

Alkire, M. T., Hudetz, A. G., and Tononi, G. (2008). Consciousness and anesthesia. Science 322, 876-880. doi: 10.1126/science.1149213

Antognini, J. F., and Carstens, E. (1998). Macroscopic sites of anesthetic action: brain versus spinal cord. Toxicol. Lett. 10, 51-58. doi: 10.1016/S0378-4274(98) 00164-7

Antognini, J. F., Carstens, E., Tabo, E., and Buzin, V. (1998). Effect of differential delivery of isoflurane to head and torso on lumbar dorsal horn activity. Anesthesiology 88, 1055-1061. doi: 10.1097/00000542-199804000-00026

Antognini, J. F., and Schwartz, K. (1993). Exaggerated anesthetic requirements in the preferentially anesthetized brain. Anesthesiology 79, 1244-1249. doi: 10.1097/00000542-199312000-00015

Avramescu, S., Wang, D. S., Lecker, I., To, W. T., Penna, A., Whissell, P. D., et al. (2016). Inflammation increases neuronal sensitivity to general anesthetics. Anesthesiology 124, 417-427. doi: 10.1097/ALN.0000000000000943

Bannai, H., Levi, S., Schweizer, C., Inoue, T., Launey, T., Racine, V., et al. (2009). Activity-dependent tuning of inhibitory neurotransmission based on GABAAR diffusion dynamics. Neuron 62, 670-682. doi: 10.1016/j.neuron.2009. 04.023

Barth, A. M., Ferando, I., and Mody, I. (2014). Ovarian cycle-linked plasticity of delta-GABAA receptor subunits in hippocampal interneurons affects gamma oscillations in vivo. Front. Cell Neurosci. 8:222. doi: 10.3389/fncel.2014.00222

Ben-Ari, Y. (2015). Commentary: GABA depolarizes immature neurons and inhibits network activity in the neonatal neocortex in vivo. Front. Cell Neurosci. 9:478. doi: 10.3389/fncel.2015.00478

Ben-Ari, Y., Gaiarsa, J. L., Tyzio, R., and Khazipov, R. (2007). GABA: a pioneer transmitter that excites immature neurons and generates primitive oscillations. Physiol. Rev. 87, 1215-1284. doi: 10.1152/physrev.00017.2006

Bieda, M. C., Su, H., and Maciver, M. B. (2009). Anesthetics discriminate between tonic and phasic gamma-aminobutyric acid receptors on hippocampal CA1 neurons. Anesth. Analg. 108, 484-490. doi: 10.1213/ane.0b013e31819 04571 key concepts/references as well as co-wrote and co-edited the manuscript.

\section{FUNDING}

This work was supported by the James S. McDonnell Foundation (award number 220020346, PG), the National Institute of Health (F31NS086370, IS) and the U.S. Department of Veterans Affairs (award number BX001677, PG).

\section{ACKNOWLEDGMENT}

We acknowledge that part of this work appears in dissertation form (Speigel, 2017).

Bjornstrom, K., Turina, D., Strid, T., Sundqvist, T., and Eintrei, C. (2014). Orexin A inhibits propofol-induced neurite retraction by a phospholipase D/protein kinase Cepsilon-dependent mechanism in neurons. PLoS ONE 9:e97129. doi: 10.1371/journal.pone.0097129

Bogdanov, Y., Michels, G., Armstrong-Gold, C., Haydon, P. G., Lindstrom, J., Pangalos, M., et al. (2006). Synaptic GABAA receptors are directly recruited from their extrasynaptic counterparts. EMBO J. 25, 4381-4389. doi: 10.1038/sj. emboj.7601309

Bohlhalter, S., Weinmann, O., Mohler, H., and Fritschy, J. M. (1996). Laminar compartmentalization of GABAA-receptor subtypes in the spinal cord: an immunohistochemical study. J. Neurosci. 16, 283-297.

Bonin, R. P., Martin, L. J., MacDonald, J. F., and Orser, B. A. (2007). Alpha5GABAA receptors regulate the intrinsic excitability of mouse hippocampal pyramidal neurons. J. Neurophysiol. 98, 2244-2254. doi: 10.1152/jn.00482.2007

Bonin, R. P., and Orser, B. A. (2008). GABA(A) receptor subtypes underlying general anesthesia. Pharmacol. Biochem. Behav. 90, 105-112. doi: 10.1016/j.pbb. 2007.12.011

Brady, M. L., and Jacob, T. C. (2015). Synaptic localization of alpha5 GABA (A) receptors via gephyrin interaction regulates dendritic outgrowth and spine maturation. Dev. Neurobiol. 75, 1241-1251. doi: 10.1002/dneu.22280

Brown, E. N., Lydic, R., and Schiff, N. D. (2010). General anesthesia, sleep, and coma. N. Engl. J. Med. 363, 2638-2650. doi: 10.1056/NEJMra0 808281

Brown, E. N., Purdon, P. L., and Van Dort, C. J. (2011). General anesthesia and altered states of arousal: a systems neuroscience analysis. Annu. Rev. Neurosci. 34, 601-628. doi: 10.1146/annurev-neuro-060909-153200

Browne, S. H., Kang, J., Akk, G., Chiang, L. W., Schulman, H., Huguenard, J. R., et al. (2001). Kinetic and pharmacological properties of GABA(A) receptors in single thalamic neurons and GABA(A) subunit expression. J. Neurophysiol. 86, 2312-2322.

Caraiscos, V. B., Elliott, E. M., You-Ten, K. E., Cheng, V. Y., Belelli, D., Newell, J. G., et al. (2004a). Tonic inhibition in mouse hippocampal CA1 pyramidal neurons is mediated by alpha5 subunit-containing gamma-aminobutyric acid type A receptors. Proc. Natl. Acad. Sci. U.S.A. 101, 3662-3667. doi: 10.1073/ pnas.0307231101

Caraiscos, V. B., Newell, J. G., You-Ten, K. E., Elliott, E. M., Rosahl, T. W., Wafford, K. A., et al. (2004b). Selective enhancement of tonic GABAergic inhibition in murine hippocampal neurons by low concentrations of the volatile anesthetic isoflurane. J. Neurosci. 24, 8454-8458. doi: 10.1523/JNEUROSCI.206304.2004

Chander, D., Garcia, P. S., MacColl, J. N., Illing, S., and Sleigh, J. W. (2014). Electroencephalographic variation during end maintenance and emergence from surgical anesthesia. PLoS ONE 9:e106291. doi: 10.1371/journal.pone. 0106291

Correia, A. C., Silva, P. C., and da Silva, B. A. (2012). Malignant hyperthermia: clinical and molecular aspects. Rev. Bras. Anestesiol. 62, 820-837. doi: 10.1016/ S0034-7094(12)70182-4 
Coulter, D. A., and Carlson, G. C. (2007). Functional regulation of the dentate gyrus by GABA-mediated inhibition. Prog. Brain Res. 163, 235-243. doi: 10.1016/S0079-6123(07)63014-3

de Groote, L., and Linthorst, A. C. (2007). Exposure to novelty and forced swimming evoke stressor-dependent changes in extracellular GABA in the rat hippocampus. Neuroscience 148, 794-805. doi: 10.1016/j.neuroscience.2007. 06.030

Drafts, B. C., and Fisher, J. L. (2006). Identification of structures within GABAA receptor alpha subunits that regulate the agonist action of pentobarbital. J. Pharmacol. Exp. Ther. 318, 1094-1101. doi: 10.1124/jpet.106.104844

Farrant, M., and Nusser, Z. (2005). Variations on an inhibitory theme: phasic and tonic activation of GABA(A) receptors. Nat. Rev. Neurosci. 6, 215-229. doi: $10.1038 / \mathrm{nrn} 1625$

Ferando, I., and Mody, I. (2012). GABAA receptor modulation by neurosteroids in models of temporal lobe epilepsies. Epilepsia 53(Suppl. 9), 89-101. doi: 10.1111/ epi. 12038

Franks, N. P. (2006). Molecular targets underlying general anaesthesia. Br. J. Pharmacol. 147(Suppl. 1), S72-S81. doi: 10.1038/sj.bjp.0706441

Ganguly, K., Schinder, A. F., Wong, S. T., and Poo, M. (2001). GABA itself promotes the developmental switch of neuronal GABAergic responses from excitation to inhibition. Cell 105, 521-532. doi: 10.1016/S0092-8674(01) 00341-5

Gao, B., and Fritschy, J. M. (1994). Selective allocation of GABAA receptors containing the alpha 1 subunit to neurochemically distinct subpopulations of rat hippocampal interneurons. Eur. J. Neurosci. 6, 837-853. doi: 10.1111/j.14609568.1994.tb00994.x

Garcia, P. S., Kolesky, S. E., and Jenkins, A. (2010). General anesthetic actions on GABA(A) receptors. Curr. Neuropharmacol. 8, 2-9. doi: 10.2174/ 157015910790909502

Gonzalez, C., Moss, S. J., and Olsen, R. W. (2012). Ethanol promotes clathrin adaptor-mediated endocytosis via the intracellular domain of delta-containing GABAA receptors. J. Neurosci. 32, 17874-17881. doi: 10.1523/JNEUROSCI. 2535- 12.2012

Guldenmund, P., Gantner, I. S., Baquero, K., Das, T., Demertzi, A., Boveroux, P., et al. (2016). Propofol-induced frontal cortex disconnection: a study of restingstate networks, total brain connectivity, and mean BOLD signal oscillation frequencies. Brain Connect. 6, 225-237. doi: 10.1089/brain.2015.0369

Harrison, N. L. (2007). Mechanisms of sleep induction by GABA(A) receptor agonists. J. Clin. Psychiatry 68(Suppl. 5), 6-12.

Hausrat, T. J., Muhia, M., Gerrow, K., Thomas, P., Hirdes, W., Tsukita, S., et al. (2015). Radixin regulates synaptic GABAA receptor density and is essential for reversal learning and short-term memory. Nat. Commun. 6, 6872. doi: $10.1038 /$ ncomms7872

Hemmings, H. C. Jr., and Egan, T. D. (2013). Pharmacology and Physiology for Anesthesia. Philadelphia, PA: Elsevier.

Hentschke, H., Benkwitz, C., Banks, M. I., Perkins, M. G., Homanics, G. E., and Pearce, R. A. (2009). Altered GABAA,slow inhibition and network oscillations in mice lacking the GABAA receptor beta3 subunit. J. Neurophysiol. 102, 3643-3655. doi: 10.1152/jn.00651.2009

Herd, M. B., Haythornthwaite, A. R., Rosahl, T. W., Wafford, K. A., Homanics, G. E., Lambert, J. J., et al. (2008). The expression of GABAA beta subunit isoforms in synaptic and extrasynaptic receptor populations of mouse dentate gyrus granule cells. J. Physiol. 586, 989-1004. doi: 10.1113/jphysiol.2007. 146746

Hu, Y., Lund, I. V., Gravielle, M. C., Farb, D. H., Brooks-Kayal, A. R., and Russek, S. J. (2008). Surface expression of GABAA receptors is transcriptionally controlled by the interplay of cAMP-response element-binding protein and its binding partner inducible cAMP early repressor. J. Biol. Chem. 283, 9328-9340. doi: 10.1074/jbc.M705110200

Huang, S., Hokenson, K., Bandyopadhyay, S., Russek, S. J., and Kirkwood, A. (2015). Brief dark exposure reduces tonic inhibition in visual cortex. J. Neurosci. 35, 15916-15920. doi: 10.1523/JNEUROSCI.1813-15.2015

Jacob, T. C., Bogdanov, Y. D., Magnus, C., Saliba, R. S., Kittler, J. T., Haydon, P. G., et al. (2005). Gephyrin regulates the cell surface dynamics of synaptic GABAA receptors. J. Neurosci. 25, 10469-10478. doi: 10.1523/JNEUROSCI. 2267-05.2005

Jechlinger, M., Pelz, R., Tretter, V., Klausberger, T., and Sieghart, W. (1998). Subunit composition and quantitative importance of hetero-oligomeric receptors: GABAA receptors containing alpha6 subunits. J. Neurosci. 18, 2449-2457.

Jenkins, A., Greenblatt, E. P., Faulkner, H. J., Bertaccini, E., Light, A., Lin, A., et al. (2001). Evidence for a common binding cavity for three general anesthetics within the GABAA receptor. J. Neurosci. 21, RC136.

Jia, F., Pignataro, L., Schofield, C. M., Yue, M., Harrison, N. L., and Goldstein, P. A. (2005). An extrasynaptic GABAA receptor mediates tonic inhibition in thalamic VB neurons. J. Neurophysiol. 94, 4491-4501. doi: 10.1152/jn.00421. 2005

Jia, F., Yue, M., Chandra, D., Homanics, G. E., Goldstein, P. A., and Harrison, N. L. (2008). Isoflurane is a potent modulator of extrasynaptic GABA(A) receptors in the thalamus. J. Pharmacol. Exp. Ther. 324, 1127-1135. doi: 10.1124/jpet.107. 134569

Joshi, S., and Kapur, J. (2009). Slow intracellular accumulation of GABA(A) receptor delta subunit is modulated by brain-derived neurotrophic factor. Neuroscience 164, 507-519. doi: 10.1016/j.neuroscience.2009. 08.008

Jung, M. W., and McNaughton, B. L. (1993). Spatial selectivity of unit activity in the hippocampal granular layer. Hippocampus 3, 165-182. doi: 10.1002/hipo. 450030209

Kittler, J. T., Thomas, P., Tretter, V., Bogdanov, Y. D., Haucke, V., Smart, T. G., et al. (2004). Huntingtin-associated protein 1 regulates inhibitory synaptic transmission by modulating gamma-aminobutyric acid type A receptor membrane trafficking. Proc. Natl. Acad. Sci. U.S.A. 101, 12736-12741. doi: 10.1073/pnas.0401860101

Knierim, J. J., and Neunuebel, J. P. (2016). Tracking the flow of hippocampal computation: pattern separation, pattern completion, and attractor dynamics. Neurobiol. Learn. Mem. 129, 38-49. doi: 10.1016/j.nlm.2015.10.008

Kretschmannova, K., Hines, R. M., Revilla-Sanchez, R., Terunuma, M., Tretter, V., Jurd, R., et al. (2013). Enhanced tonic inhibition influences the hypnotic and amnestic actions of the intravenous anesthetics etomidate and propofol. J. Neurosci. 33, 7264-7273. doi: 10.1523/JNEUROSCI.5475-12.2013

Kuver, A., and Smith, S. S. (2016). Flumazenil decreases surface expression of alpha4beta2delta GABAA receptors by increasing the rate of receptor internalization. Brain Res. Bull. 120, 131-143. doi: 10.1016/j.brainresbull.2015. 11.015

Lee, V., and Maguire, J. (2014). The impact of tonic GABAA receptor-mediated inhibition on neuronal excitability varies across brain region and cell type. Front. Neural Circuits 8:3. doi: 10.3389/fncir.2014.00003

Lerma, J., Herranz, A. S., Herreras, O., Abraira, V., and Martin del Rio, R. (1986). In vivo determination of extracellular concentration of amino acids in the rat hippocampus. A method based on brain dialysis and computerized analysis. Brain Res. 384, 145-155. doi: 10.1016/0006-8993(86)91230-8

Li, Y., Wu, Y., Li, R., Wang, C., Jia, N., Zhao, C., et al. (2015). Propofol regulates the surface expression of GABAA receptors: implications in synaptic inhibition. Anesth. Analg. 121, 1176-1183. doi: 10.1213/ANE.0000000000000884

Li, Z. X., Yu, H. M., and Jiang, K. W. (2013). Tonic GABA inhibition in hippocampal dentate granule cells: its regulation and function in temporal lobe epilepsies. Acta Physiol. (Oxf) 209, 199-211. doi: 10.1111/apha.12148

Liang, J., Suryanarayanan, A., Abriam, A., Snyder, B., Olsen, R. W., and Spigelman, I. (2007). Mechanisms of reversible GABAA receptor plasticity after ethanol intoxication. J. Neurosci. 27, 12367-12377. doi: 10.1523/JNEUROSCI. 2786-07.2007

Llinas, R. R., and Steriade, M. (2006). Bursting of thalamic neurons and states of vigilance. J. Neurophysiol. 95, 3297-3308. doi: 10.1152/jn.00166.2006

Lothman, E. W., Stringer, J. L., and Bertram, E. H. (1992). The dentate gyrus as a control point for seizures in the hippocampus and beyond. Epilepsy Res. Suppl. 7, 301-313.

Luscher, B., Fuchs, T., and Kilpatrick, C. L. (2011). GABAA receptor traffickingmediated plasticity of inhibitory synapses. Neuron 70, 385-409. doi: 10.1016/j. neuron.2011.03.024

Maguire, J. L., Stell, B. M., Rafizadeh, M., and Mody, I. (2005). Ovarian cycle-linked changes in $\mathrm{GABA}(\mathrm{A})$ receptors mediating tonic inhibition alter seizure susceptibility and anxiety. Nat. Neurosci. 8, 797-804. doi: 10.1038/ nn 1469

Mann, E. O., and Mody, I. (2010). Control of hippocampal gamma oscillation frequency by tonic inhibition and excitation of interneurons. Nat. Neurosci. 13, 205-212. doi: $10.1038 / \mathrm{nn} .2464$ 
Mashour, G. A. (2014). Top-down mechanisms of anesthetic-induced unconsciousness. Front. Syst. Neurosci. 8:115. doi: 10.3389/fnsys.2014.00115

Mashour, G. A., Forman, S. A., and Campagna, J. A. (2005). Mechanisms of general anesthesia: from molecules to mind. Best Pract. Res. Clin. Anaesthesiol. 19, 349-364.

May, A. C., Fleischer, W., Kletke, O., Haas, H. L., and Sergeeva, O. A. (2013). Benzodiazepine-site pharmacology on GABAA receptors in histaminergic neurons. Br. J. Pharmacol. 170, 222-232. doi: 10.1111/bph.12280

McKernan, R. M., and Whiting, P. J. (1996). Which GABAA-receptor subtypes really occur in the brain? Trends Neurosci. 19, 139-143.

Milenkovic, I., Vasiljevic, M., Maurer, D., Hoger, H., Klausberger, T., and Sieghart, W. (2013). The parvalbumin-positive interneurons in the mouse dentate gyrus express GABAA receptor subunits alpha1, beta2, and delta along their extrasynaptic cell membrane. Neuroscience 254, 80-96. doi: 10.1016/j. neuroscience.2013.09.019

Miller, P. S., and Aricescu, A. R. (2014). Crystal structure of a human GABAA receptor. Nature 512, 270-275. doi: 10.1038/nature13293

Mody, I., Glykys, J., and Wei, W. (2007). A new meaning for "Gin \& Tonic": tonic inhibition as the target for ethanol action in the brain. Alcohol 41, 145-153. doi: 10.1016/j.alcohol.2007.03.009

Mody, I., and Pearce, R. A. (2004). Diversity of inhibitory neurotransmission through GABA(A) receptors. Trends Neurosci. 27, 569-575. doi: 10.1016/j.tins. 2004.07.002

Monk, T. G., Saini, V., Weldon, B. C., and Sigl, J. C. (2005). Anesthetic management and one-year mortality after noncardiac surgery. Anesth. Analg. 100, 4-10. doi: 10.1213/01.ANE.0000147519.82841.5E

Mortensen, M., and Smart, T. G. (2006). Extrasynaptic alphabeta subunit GABAA receptors on rat hippocampal pyramidal neurons. J. Physiol. 577(Pt 3), 841-856. doi: 10.1113/jphysiol.2006.117952

Murphey, D. K., Herman, A. M., and Arenkiel, B. R. (2014). Dissecting inhibitory brain circuits with genetically-targeted technologies. Front. Neural Circuits 8:124. doi: $10.3389 /$ fncir.2014.00124

Nakamura, Y., Darnieder, L. M., Deeb, T. Z., and Moss, S. J. (2015). Regulation of GABAARs by phosphorylation. Adv. Pharmacol. 72, 97-146. doi: 10.1016/bs. apha.2014.11.008

Nury, H., Van Renterghem, C., Weng, Y., Tran, A., Baaden, M., Dufresne, V., et al. (2011). X-ray structures of general anaesthetics bound to a pentameric ligand-gated ion channel. Nature 469, 428-431. doi: 10.1038/nature 09647

Nusser, Z., Sieghart, W., Benke, D., Fritschy, J. M., and Somogyi, P. (1996). Differential synaptic localization of two major gamma-aminobutyric acid type A receptor alpha subunits on hippocampal pyramidal cells. Proc. Natl. Acad. Sci. U.S.A. 93, 11939-11944. doi: 10.1073/pnas.93.21.11939

Nusser, Z., Sieghart, W., and Somogyi, P. (1998). Segregation of different GABAA receptors to synaptic and extrasynaptic membranes of cerebellar granule cells. J. Neurosci. 18, 1693-1703.

Olsen, R. W., and Sieghart, W. (2008). International Union of Pharmacology. LXX. Subtypes of gamma-aminobutyric acid(A) receptors: classification on the basis of subunit composition, pharmacology, and function. Update. Pharmacol. Rev. 60, 243-260. doi: 10.1124/pr.108.00505

Pan, J. Z., Xi, J., Eckenhoff, M. F., and Eckenhoff, R. G. (2008). Inhaled anesthetics elicit region-specific changes in protein expression in mammalian brain. Proteomics 8, 2983-2992. doi: 10.1002/pmic.200800057

Paul, J., Zeilhofer, H. U., and Fritschy, J. M. (2012). Selective distribution of GABA(A) receptor subtypes in mouse spinal dorsal horn neurons and primary afferents. J. Comp. Neurol. 520, 3895-3911. doi: 10.1002/cne.23129

Pavlov, I., Savtchenko, L. P., Song, I., Koo, J., Pimashkin, A., Rusakov, D. A., et al. (2014). Tonic GABAA conductance bidirectionally controls interneuron firing pattern and synchronization in the CA3 hippocampal network. Proc. Natl. Acad. Sci. U.S.A. 111, 504-509. doi: 10.1073/pnas.1308388110

Peng, Z., Huang, C. S., Stell, B. M., Mody, I., and Houser, C. R. (2004). Altered expression of the delta subunit of the GABAA receptor in a mouse model of temporal lobe epilepsy. J. Neurosci. 24, 8629-8639. doi: 10.1523/JNEUROSCI. 2877-04.2004

Platholi, J., Herold, K. F., Hemmings, H. C. Jr., and Halpain, S. (2014). Isoflurane reversibly destabilizes hippocampal dendritic spines by an actin-dependent mechanism. PLoS ONE 9:e102978. doi: 10.1371/journal.pone.0102978
Raines, D. E., Claycomb, R. J., and Forman, S. A. (2003). Modulation of GABA(A) receptor function by nonhalogenated alkane anesthetics: the effects on agonist enhancement, direct activation, and inhibition. Anesth. Analg. 96, $112-118$.

Rau, V., Iyer, S. V., Oh, I., Chandra, D., Harrison, N., Eger, E. I. II. et al. (2009). Gamma-aminobutyric acid type A receptor alpha 4 subunit knockout mice are resistant to the amnestic effect of isoflurane. Anesth. Analg. 109, 1816-1822. doi: 10.1213/ANE.0b013e3181bf6ae6

Rovo, Z., Matyas, F., Bartho, P., Slezia, A., Lecci, S., Pellegrini, C., et al. (2014). Phasic, nonsynaptic GABA-A receptor-mediated inhibition entrains thalamocortical oscillations. J. Neurosci. 34, 7137-7147. doi: 10.1523/ JNEUROSCI.4386-13.2014

Senzai, Y., and Buzsaki, G. (2017). Physiological properties and behavioral correlates of hippocampal granule cells and mossy cells. Neuron 93, 691-704.e5. doi: 10.1016/j.neuron.2016.12.011

Silber, M. H., and Rye, D. B. (2001). Solving the mysteries of narcolepsy: the hypocretin story. Neurology 56, 1616-1618. doi: 10.1212/WNL.56.12.1616

Speigel, I. (2017). The Role of Calcineurin in the Recovery of Cognitive Function From Isoflurane Anesthesia. Ph.D. thesis, Emory University, Atlanta, GA.

Sperk, G., Schwarzer, C., Tsunashima, K., Fuchs, K., and Sieghart, W. (1997). GABA(A) receptor subunits in the rat hippocampus I: immunocytochemical distribution of 13 subunits. Neuroscience 80, 987-1000. doi: 10.1016/S03064522(97)00146-2

Stell, B. M., and Mody, I. (2002). Receptors with different affinities mediate phasic and tonic GABA(A) conductances in hippocampal neurons. J. Neurosci. 22, RC223.

Steriade, M. (2000). Corticothalamic resonance, states of vigilance and mentation. Neuroscience 101, 243-276. doi: 10.1016/S0306-4522(00)00353-5

Sur, C., Farrar, S. J., Kerby, J., Whiting, P. J., Atack, J. R., and McKernan, R. M. (1999a). Preferential coassembly of alpha4 and delta subunits of the gamma-aminobutyric acidA receptor in rat thalamus. Mol. Pharmacol. 56, $110-115$.

Sur, C., Fresu, L., Howell, O., McKernan, R. M., and Atack, J. R. (1999b). Autoradiographic localization of alpha5 subunit-containing GABAA receptors in rat brain. Brain Res. 822, 265-270.

Tossman, U., Jonsson, G., and Ungerstedt, U. (1986). Regional distribution and extracellular levels of amino acids in rat central nervous system. Acta Physiol. Scand. 127, 533-545. doi: 10.1111/j.1748-1716.1986.tb07938.x

Tretter, V., Mukherjee, J., Maric, H. M., Schindelin, H., Sieghart, W., and Moss, S. J. (2012). Gephyrin, the enigmatic organizer at GABAergic synapses. Front. Cell Neurosci. 6:23. doi: 10.3389/fncel.2012.00023

Triller, A., and Choquet, D. (2005). Surface trafficking of receptors between synaptic and extrasynaptic membranes: and yet they do move! Trends Neurosci. 28, 133-139. doi: 10.1016/j.tins.2005.01.001

van Rijnsoever, C., Sidler, C., and Fritschy, J. M. (2005). Internalized GABAreceptor subunits are transferred to an intracellular pool associated with the postsynaptic density. Eur. J. Neurosci. 21, 327-338. doi: 10.1111/j.1460-9568. 2005.03884.x

Vutskits, L., and Xie, Z. (2016). Lasting impact of general anaesthesia on the brain: mechanisms and relevance. Nat. Rev. Neurosci. 17, 705-717. doi: 10.1038/nrn. 2016.128

Wang, D. S., Zurek, A. A., Lecker, I., Yu, J., Abramian, A. M., Avramescu, S., et al. (2012). Memory deficits induced by inflammation are regulated by alpha5subunit-containing GABAA receptors. Cell Rep. 2, 488-496. doi: 10.1016/j. celrep.2012.08.022

Wei, H., and Xie, Z. (2009). Anesthesia, calcium homeostasis and Alzheimer's disease. Curr. Alzheimer Res. 6, 30-35. doi: 10.2174/156720509787313934

Weiser, B. P., Woll, K. A., Dailey, W. P., and Eckenhoff, R. G. (2014). Mechanisms revealed through general anesthetic photolabeling. Curr. Anesthesiol. Rep. 4, 57-66. doi: 10.1007/s40140-013-0040-7

Wickley, P. J., Yuge, R., Martin, B. A., Meyer, J. S., and Damron, D. S. (2009). Propofol activates and allosterically modulates recombinant protein kinase C epsilon. Anesthesiology 111, 36-43. doi: 10.1097/ALN.0b013e3181a $3274 \mathrm{~b}$

Winsky-Sommerer, R. (2009). Role of GABAA receptors in the physiology and pharmacology of sleep. Eur. J. Neurosci. 29, 1779-1794. doi: 10.1111/j.14609568.2009.06716.x 
Wisden, W., Laurie, D. J., Monyer, H., and Seeburg, P. H. (1992). The distribution of 13 GABAA receptor subunit mRNAs in the rat brain. I. Telencephalon, diencephalon, mesencephalon. J. Neurosci. 12, 1040-1062.

Wisden, W., and Seeburg, P. H. (1992). GABAA receptor channels: from subunits to functional entities. Curr. Opin. Neurobiol. 2, 263-269. doi: 10.1016/09594388(92)90113-Y

Xie, Z., and Xu, Z. (2013). General anesthetics and beta-amyloid protein. Prog. Neuropsychopharmacol. Biol. Psychiatry 47, 140-146. doi: 10.1016/j.pnpbp. 2012.08.002

Yamada, J., Furukawa, T., Ueno, S., Yamamoto, S., and Fukuda, A. (2007). Molecular basis for the GABAA receptor-mediated tonic inhibition in rat somatosensory cortex. Cereb. Cortex 17, 1782-1787. doi: 10.1093/cercor/ bhl087

Zecharia, A. Y., and Franks, N. P. (2009). General anesthesia and ascending arousal pathways. Anesthesiology 111, 695-696. doi: 10.1097/ALN.0b013e3181b061bc

Zecharia, A. Y., Nelson, L. E., Gent, T. C., Schumacher, M., Jurd, R., Rudolph, U., et al. (2009). The involvement of hypothalamic sleep pathways in general anesthesia: testing the hypothesis using the GABAA receptor beta3N265M knock-in mouse. J. Neurosci. 29, 2177-2187. doi: 10.1523/JNEUROSCI.499708.2009

Zurek, A. A., Yu, J., Wang, D. S., Haffey, S. C., Bridgwater, E. M., Penna, A., et al. (2014). Sustained increase in alpha5GABAA receptor function impairs memory after anesthesia. J. Clin. Invest. 124, 5437-5441. doi: 10.1172/JCI76669

Conflict of Interest Statement: The authors declare that the research was conducted in the absence of any commercial or financial relationships that could be construed as a potential conflict of interest.

Copyright (c) 2017 Speigel, Bichler and García. This is an open-access article distributed under the terms of the Creative Commons Attribution License (CC BY). The use, distribution or reproduction in other forums is permitted, provided the original author(s) or licensor are credited and that the original publication in this journal is cited, in accordance with accepted academic practice. No use, distribution or reproduction is permitted which does not comply with these terms. 